\title{
USLUB AL-ILTIFAT FI DIRASAT ULAMA AL-BALAGAH AL-QADIM WAL HADITS
}

\author{
Damhuri Dj. Noor, Ratni Bt. Hj. Bahri
}

damhuridjnoor@gmail.com, ummiudail@gmail.com

Institut Agama Islam Negeri Sultan Amai

Gorontalo, Indonesia

\begin{abstract}
The paper discusses the al-Iltifât language style in the Arabic tradition of science. Al-Iltifât is the transition of communication patterns in the conversation. Ontologically, al-Iltifât as a style of the language regarded as the crucial part of balaghah study, because there is no unity of definition and scope of study among scholars, even the names are quite varied. In the tradition of classical study, ulama provide various names. The scope of this al-Iltifât is limited to transition on the use of pronouns, the use of verbs, and the transition of themes in the conversation context. In contrast to modern balaghah scholars who are expanding the scope of the al-Iltifât, they are not bound by the definition and scope of the study proposed by classical scholars. They depart from the general terminology that all forms of communication pattern transition are included in the al-Iltifât category. Therefore, they develop various types that have an impressive communication pattern transition.
\end{abstract}

Keywords: Uslub, al-Iltifât, Balagah

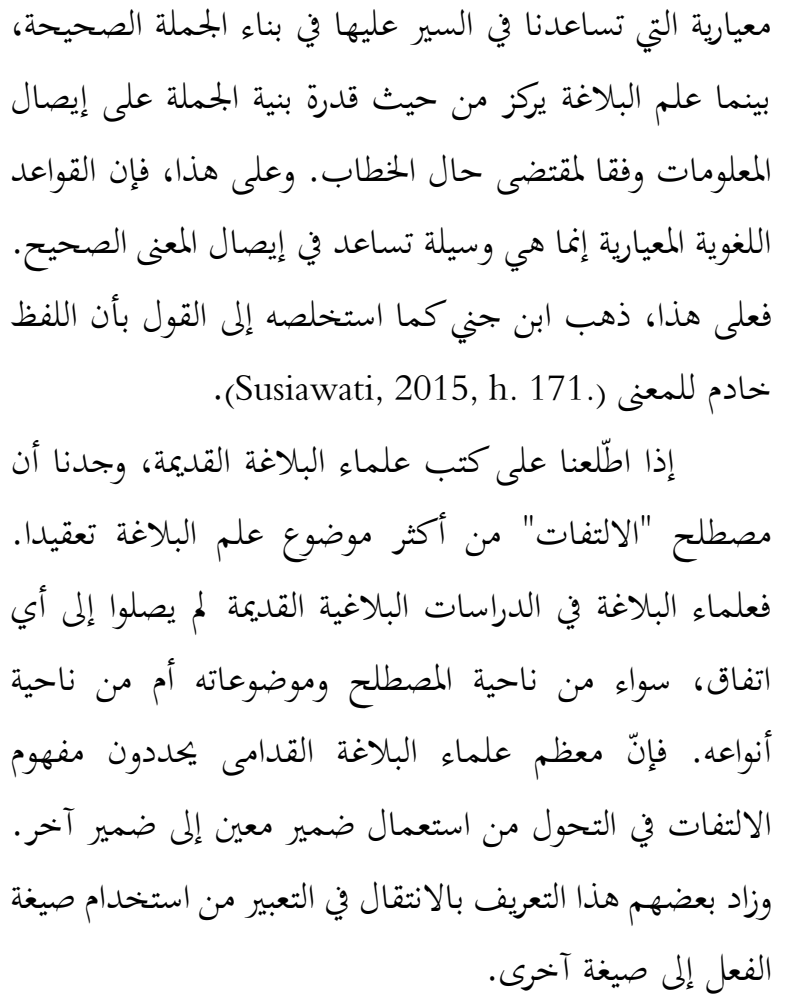


إن التوافق بين علم النحو وعلم البلاغة يتمثل في كليهما يجعلان

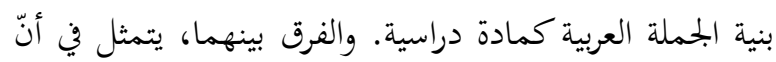
علم النحو يتناول من ناحية وظيفة وحدات لغوية في تكوين

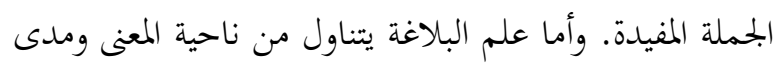

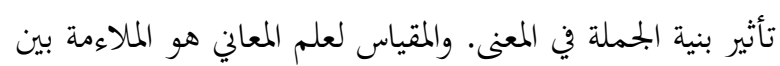

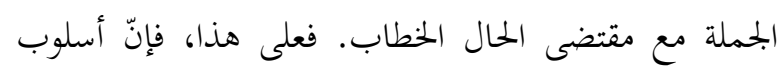

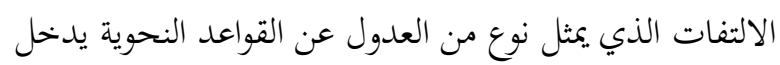

$$
\text { تحت موضوع علم المعاني. }
$$

انظلاقا من التعريف السابق ذكره، فنستخلص أنّ حقيقة

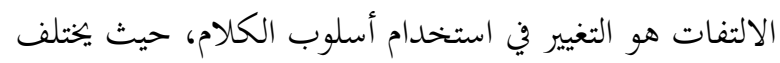
عن الأسلوب المستخدم سابقا. ولذلك، ففي محاولة فهم

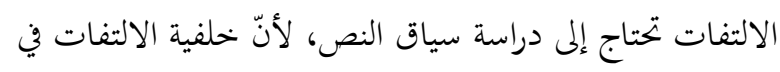
النص تتعلق بعدة نواحي. لخص Marjoko (2019, h. 64)

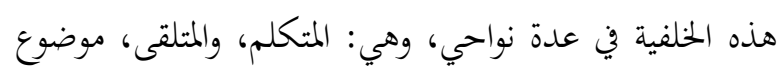

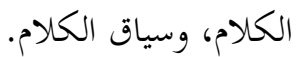

\section{تطور الدراسات عن الالتفات}

الالتفات - كنوع من أنواع فريد في اللغة العربية - شائع

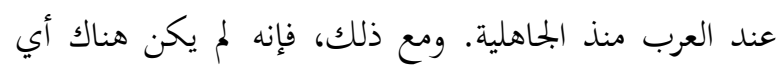

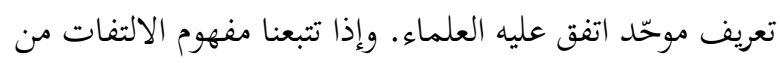

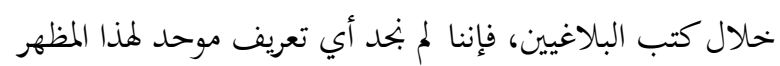

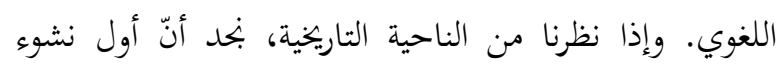
الدراسات عن الالتفات يعود إلى القرن الثاني الهجري. فعلماء

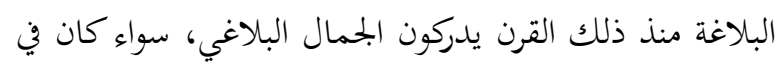

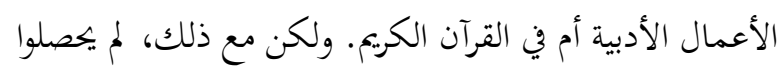

$$
\text { على مصطلح موحّد لتسميتها. }
$$

تشير المعلومات التاريخية في الكتب البلاغية إلى أنّ أول

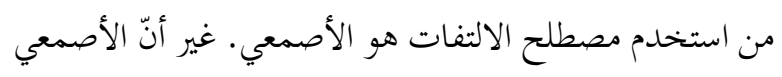

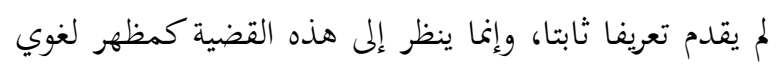
الذي له قيمة أدبية عالية. والالتفات عند الأصمعي هو التحول

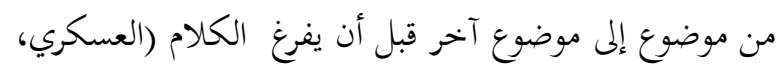

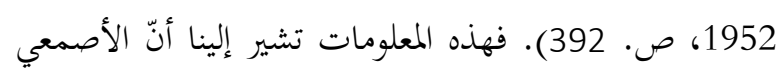

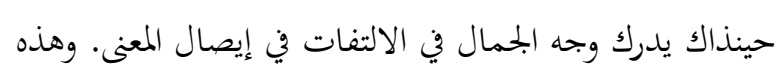

وأما علماء البلاغة الحديث، يبدو أفم يوسعون نطاق

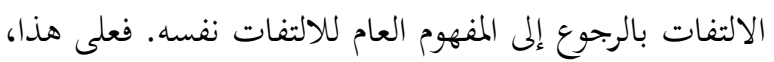

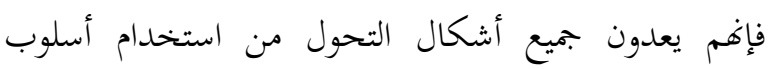

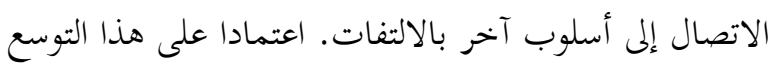

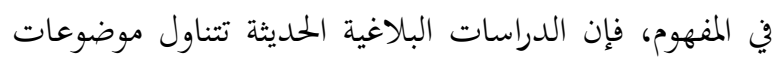

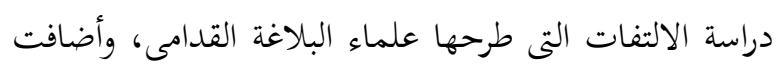
بعض الأنواع الجديدة. فيدخل في نطاق دراستهم للالتفات مثل:

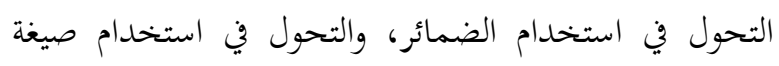
الفعل، والانتقال في استخدام الكلمات التي لها صلة دلالية،

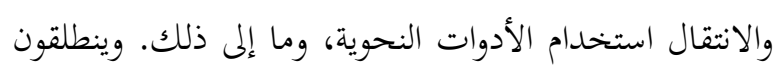

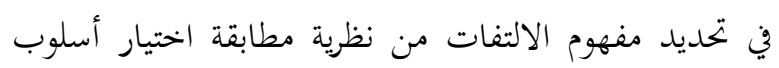
الكلام لمقتضى الحال وسياق المقام مع المعنى المقصود إيصاله.

\section{الالتفات في دراسات علماء البلاغة}

الالتفات هو أسلوب من الأساليب البلاغية. والالتفات

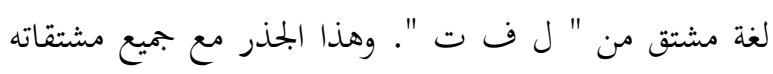

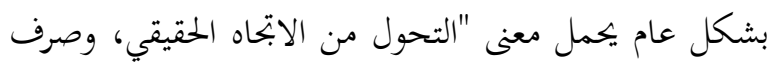
شخص ما عن رأيه، والانتقال (Wehr, 1976, p. 872).

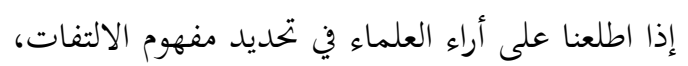

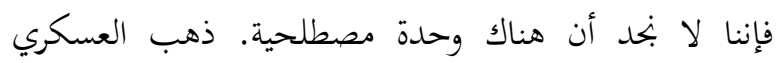
(1952، ص. 392) إلى تعريفه بأنه هو التحول من موضوع إلى وحانل

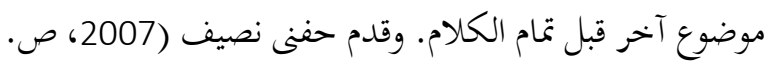

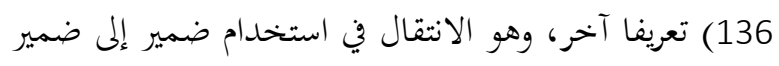

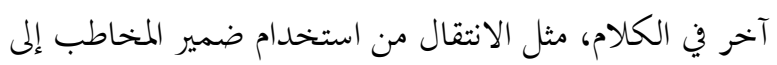

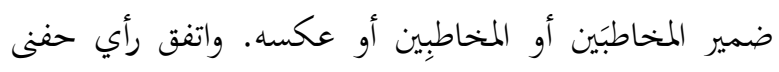
نصيف بما ذهب إليه ابن الأثير، غير أن ابن الأثير زاد في تعريفه

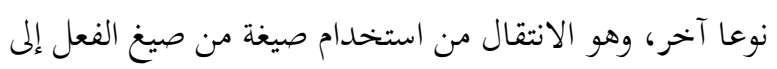

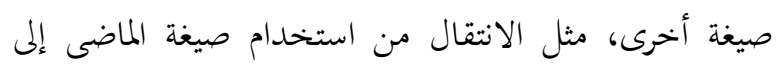

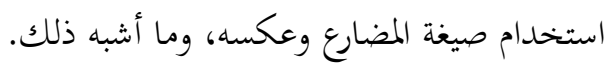

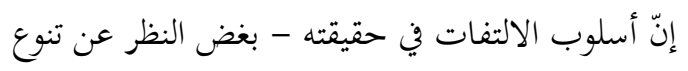

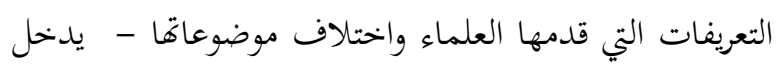
تحت الدراسة عن خروج الكلام عن القواعد النحوية المعيارية، أو ما يسمى بخروج الكلام عن مقتضى الظاهر في علم البلاغة. 
كلامه عن المحاز بعض المضوعات اللغوية، من أمثال: الاستعارة،

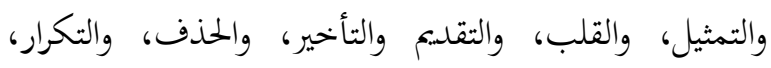

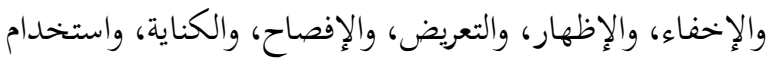

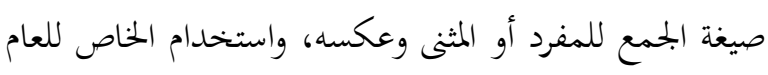
وعكسه. ويرى ابن قطيبة (2007، ص. 22-23) أنّ جميع أنواع

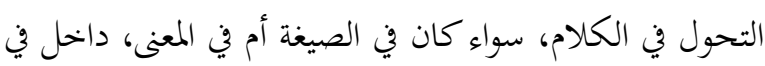
إطار موضوع الالتفات. بناء على دراسة المفاهيم السابقة، تبيّن لنا أن صور

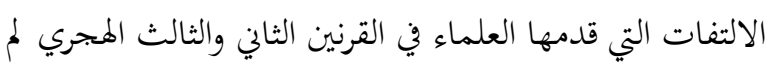

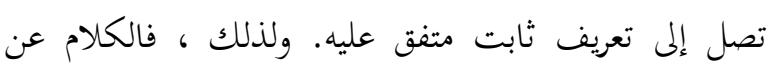

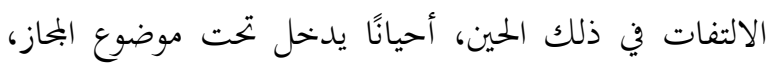
وأحيانًا استخدموا مصطلحات خحاصة، مثل الالتفات، والصرف، والإنصراف، وأحيانًا لا يؤيدون أي مصطلح للمفاهيم

$$
\text { التي قدموها. }
$$

ويُعدّ عبد الله ابن المعتز أول من عرّف الالتفات تعريفا

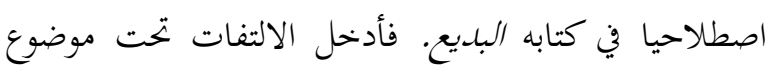

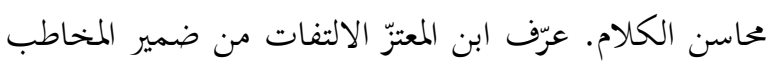

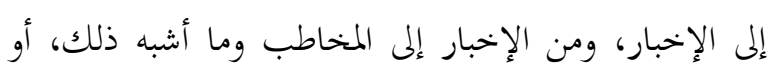
الانتقال من معنى إلى معنى آخر. والأمر الذي جدر الإشارة إليه، أنّ التعريف الذي قدمه الذه ابن المعتز هو أول تعريف اصطلاحي للإلتفات فضلا عن الإشارة

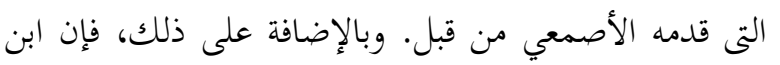

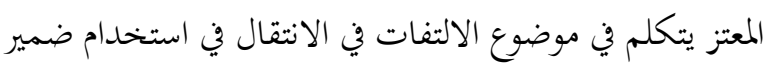
المخاطب إلى ضمير المتكلم أو الغائب. ولا يحلّد ابن المعتز موضوع الالنفات في هذه الصورة الثلاثة فحسب، بل توسّع إلى لـ

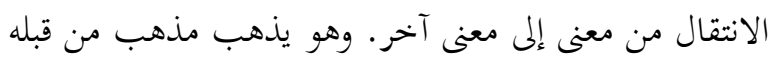
من العلماء في تسمية الالتفات بالإنصراف أو الصرف.

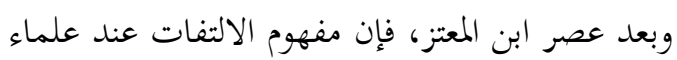
البلاغة يدور حول المفهوم السابق ذِكره مع بعض التوسع فيه. فأبو هلال العسكري مثلا، لا يقدم أي تعريف للإلتنفات، وإنما

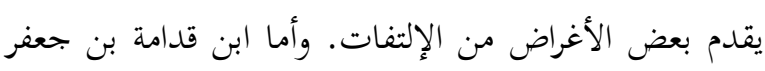

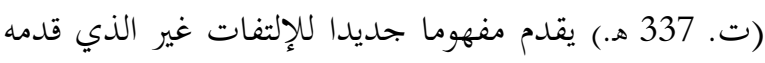

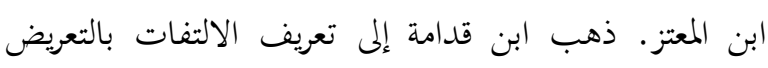

المعلومات الذي اعتمد عليه الباحثون في القول بأن الأصمعي أول من استخدم مصطلح الالتفات في الدراسات اللغوية. وعلاوة على ذلك، فإن هذه المعلومات تشير إلينا أن مصطلح الالنفات كان معروفا منذ القرن الثاني الهجري. وإنما مفهوم الالتفات في ذلك الحين مختلفًا عما يفهمه العلماء الذين جاؤوا

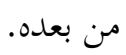
أبو عبيدة معمر المثنى (ت: 210 هـ.) مثلا عند تحليله

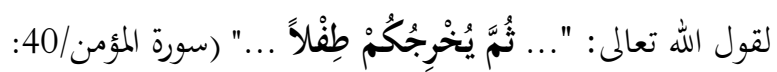

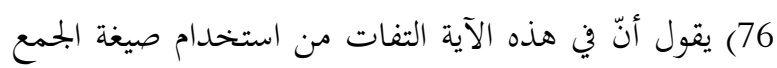

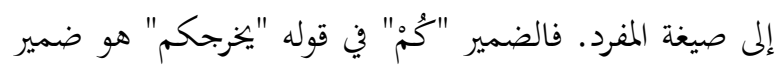

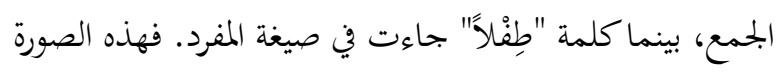

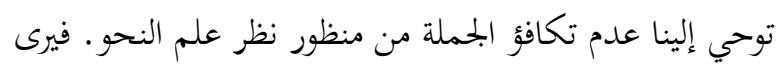

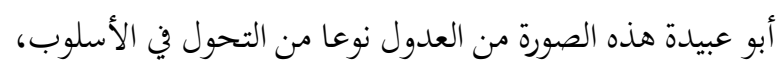

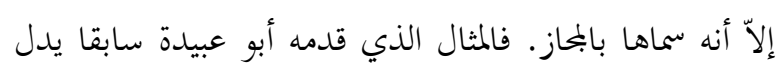

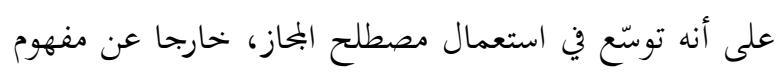

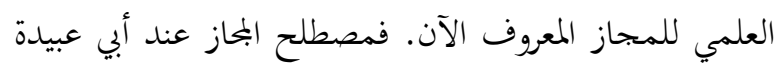

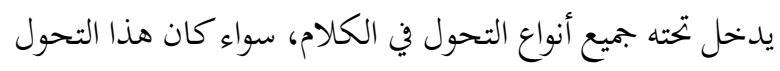

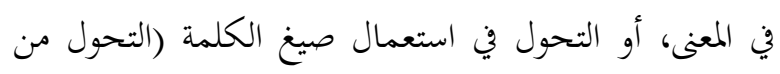

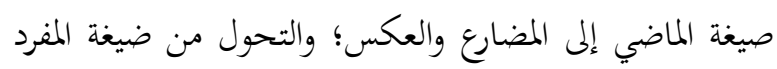

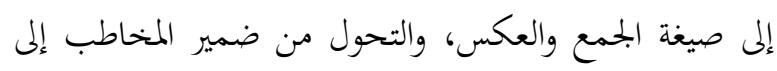

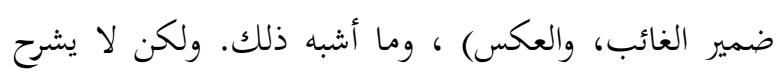

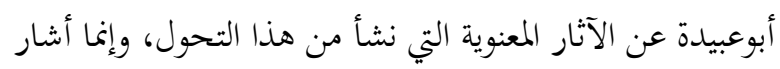

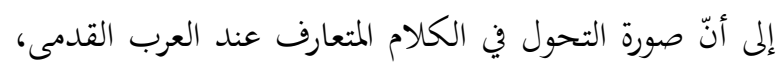
وارد في القرآن الكريع. ولا يذهب المبرد (ت. 285 هـ.) بعيدا عما ذهب إليه

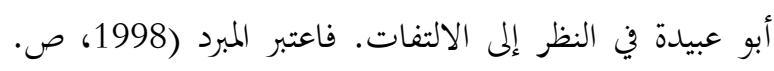

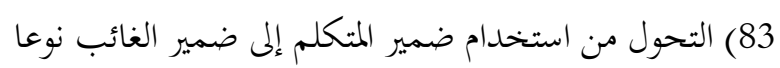

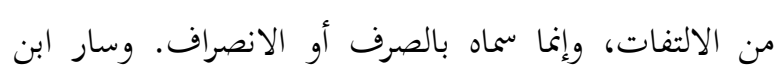
الوهاب وأسامة ابن منقذ على ما ذهب إلماه باليه المبرد في هذه الإنصراف وسار إن

وسار ابن قطيبة (ت. 276 هـ.) في كتابه تأويل مشكل القرآن إلى ما ذهب إليه أبو عبيدة. فأدخل هذه الظاهرة اللغوية

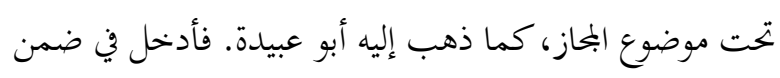




$$
\text { وحازم القرتحني (ت. } 430 \text { ه.)، وأبو طاهر البغدادي (ت. } 684 \text { هـ.). }
$$

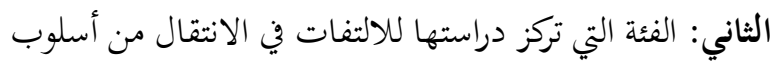

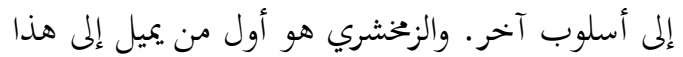

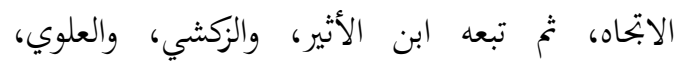

$$
\text { والسيوطي، والسكاكس وتلاميذه. }
$$

الثالث: الفئة التى توسّع في مفهوم الالتفات معتمدا على الملامح

التي قدمها العلماء من قبل. وهذا التوسيع يتمثل في

الانتقال من أسلوب إلى أسلوب آخر، والانتقال في فئ ومداء

استخدام الضمائر، والانتقال من معنى إلى معنى آخر.

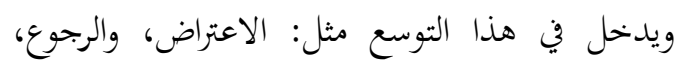
والتتميم أو الاحتراس، والاستدراك، كما ذهب في إليه

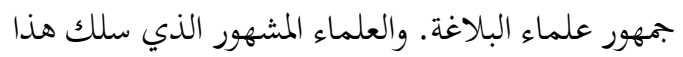
المسلك منهم: ابن رشيق القزويني (ت. 456 هـ.)، وفخر الدين الرازي (ت. 606 هـ)، وابن الإصبع

$$
\text { المصري (ت. } 654 \text { هـ.). }
$$

إنّ اختلاف علماء البلاغة في تحديد مصطلح الالتفات

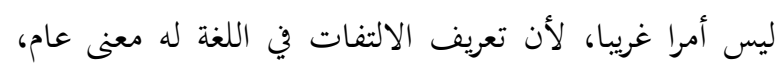

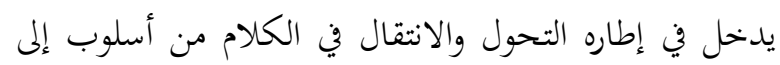
أسلوب آخر. وعلاوة على ذلك، فإنّ المصطلحات البلاغية

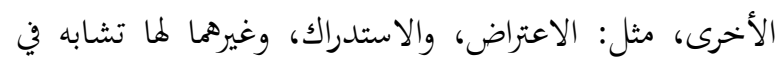
المفاهيم من حيث الانتقال في أسلوب الكلام (طبل، 1998، ص. 19). وهذه المشكلة التي تسبب في عدم وجود مفهوم موحّد تحدد مفهوم الالتفات عند العلماء البلاغيين في فترة طويلة.

بناءً على تحليلٍ لآراء علماء البلاغة حول مفهوم

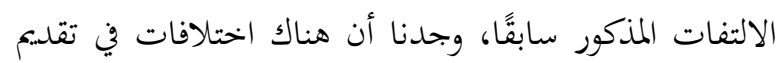
قيود مفاهيمية لهذا المصطلح. بغض النظر هذه الاختلافات، فإننا بحد أن هناك نقطة التقاء التي تجمع بين هذه المفاهيم

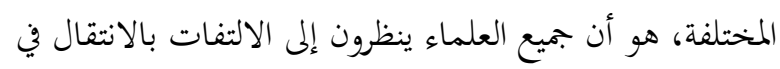
التعبير من أسلوب إلى أسلوب آخر (طبل، 1998، ص. 23. 23).

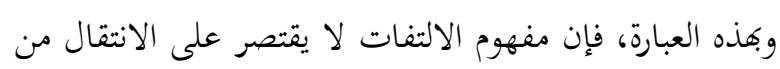

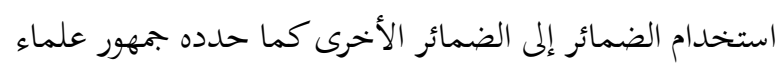

وهو إدراج فكرة جديدية تتوسط بينها وبين الفكرة (ellipsis)

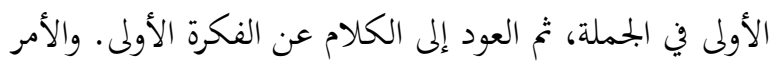

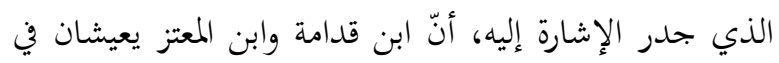
عصر واحد، غير أفما اختلفا في مفهوم الالتفات. فهذه الظاهرة

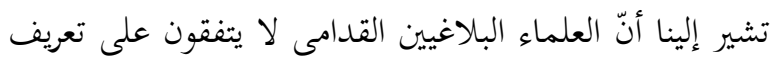

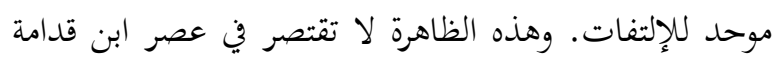
وابن المعتز فحسب، بل استمرّت إلى العصور بعدهما.

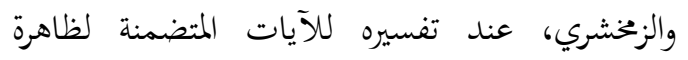

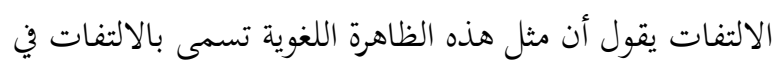

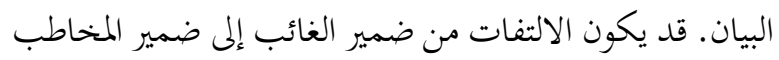
وعكسه، ومن ضمير الغائب إلى ضمير المتكلم. ومصطلح البيان الذي ذكرة الزخشري، لا يقصد به البيان بكونه علما قائما

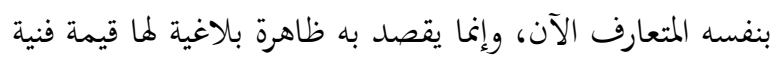

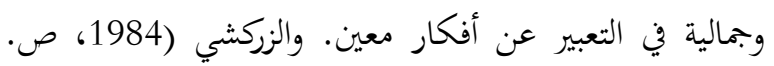
246) يقدم مصطلحا آخر للإلتفات غير الذي قدمه العلماء

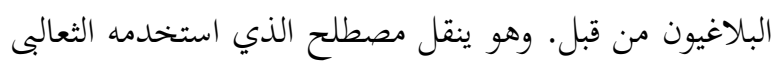
(427 هـ) وهو المتلوّّن.

وعلى الرغم من عدم وجود اتفاق في المصطلحات بين علماء البلاغة في تاريخ تطور دراسات البلاغة، فإن مصطلح

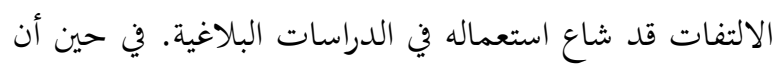

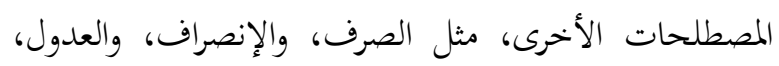

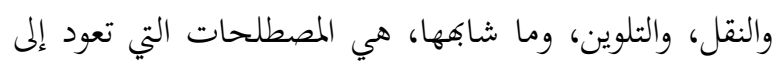
مصطلح الالتفات. وعلاوة على ذلك، أكّد ابن يعقوب المغربي

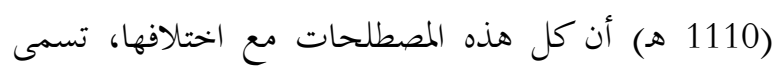

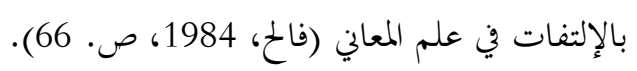
إذا لاحظنا الدراسات للإلتفات التى ذكرناها سابقا،

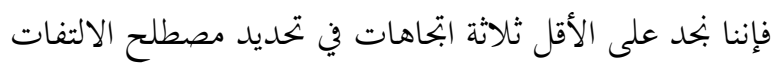
(طبل، 1998، ص. 19)، وهي: الأول: الفئة التي تستخدم مصطلح الالتفات الذي يرتبط وهي: بالمصطلحات البلاغية الأخرى، كما ذهب إليه ابن لئن

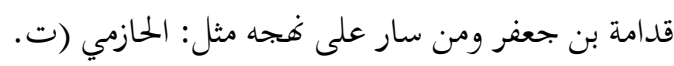
338)، وأبو هلال العسكري (ت. 395 هـ.)، والثعالبي 
الدراسات التي قاموا بها حول الالتفات يميلون إلى توصيف الأمثلة وتأكيد ماهيته في اللغة العربية عامة وفي القرآن الكريم

$$
\text { خاصة (طبل، 1998، ص. 6) ك). }
$$

يميل حسن طبل عند تعريفه للالتفات إلى مفهوم أساسي

ولغوي لهذا المصطلح. ولذلك، ينظر إلى الالتفات إلى أنه ظاهرة

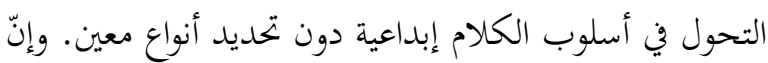

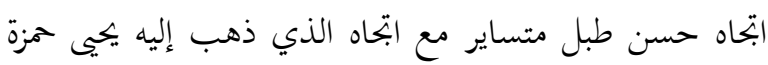

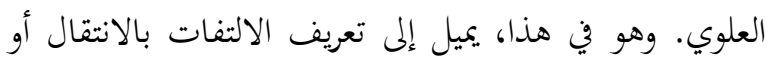

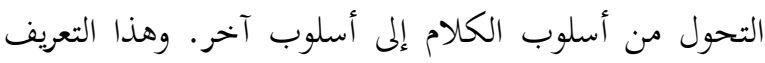
أفضل من القول بالتحول من استخدام الضمير الغائب إلى الضمير المخاطب أو من الضمير المخاطب إلى الضمير الغائب.

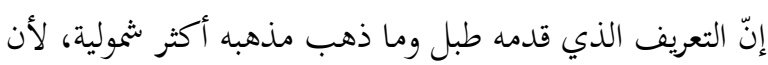
موضوع الالتفات لا يقتصر في استخدام الضمائر. والتعريفات

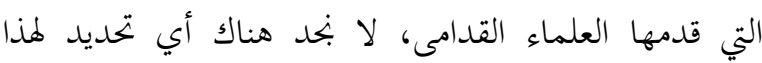
المصطلح، وإنما تتمثل في تقديم الأمثلة للالتفات (ابن حمزة، 1914، ص. 132). فذهب طبل إلى استيعاب معظم وجهات

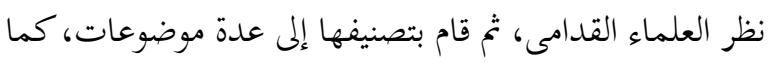

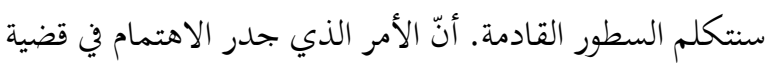

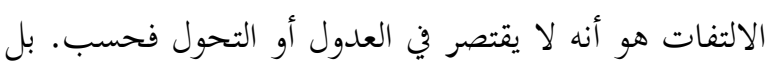

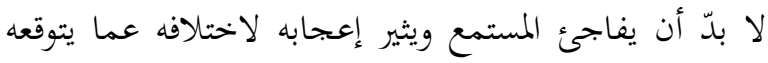

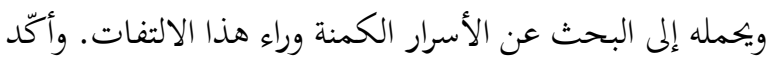
2018, h. ) Moh. Makinuddin كما عنه D. Hidayat 172) بأن من أغرض الالتفات هي النتويع في طرق التعبير لأن

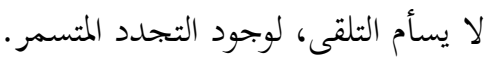

\section{أنواع الالثفات في دراسات العلماء القدامى}

وفي المحاولة في تصنيف أنواع الالتفات، لا يمكننا

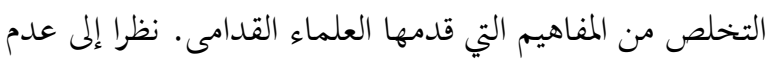
وجود اتساق مفاهيم العلماء حول حدود الالتفات، فالعلماء مختلفون في تحديد نطاقه في كتبهم. وذهب بعض العاء العلماء إلى تضييق نطاق دراستهم، وذهب بعضهم إلى توسيعه بعيدا عن التعريفات التى شاعت بين علماء البلاغة.
البلاغة، ولكن له معنى واسع يدخل تحته جميع صور الانتقال في

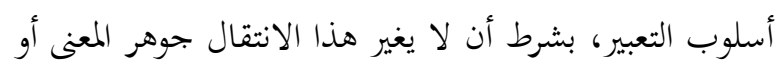

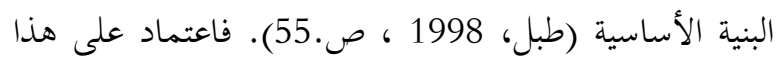
المفهوم، يمكننا بتجنب التناقضات والاختلافات القائمة وتطوير موضوع دراسة الالتفات. انطلاقا من الدراسات المصطلحية سابقا، فإنها تعطينا تصورا بأنّ مصطلح الالتفات نسبي. وإنّ العلماء يتأثرون بخبرتم الأدبية في تحديد مصلح الالتفات. فعلى سبيل المثال، في القرن

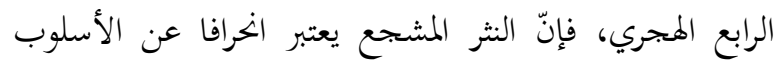

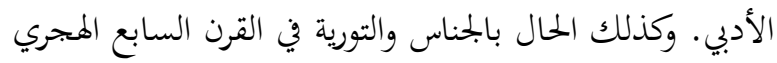

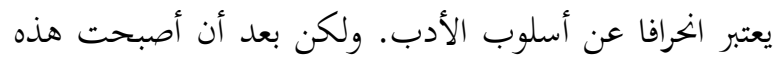

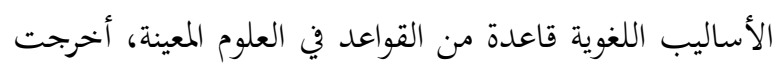

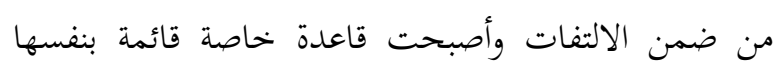
(الخرشة، 2008، ص. 30). بصرف النظر عن تنوع التعاريف والقيود المفروضة على الالتفات، فمن المؤكد أن العلماء بذلوا جهدا كبيرا في تحديد

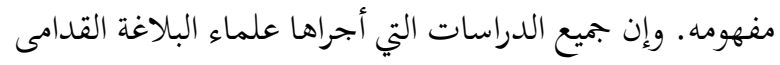

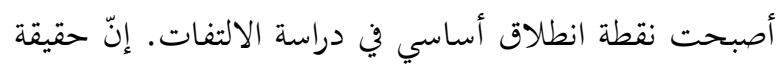
الالنفات هي التغيير أو التحول في أسلوب الكلام عن أسلوب دربه

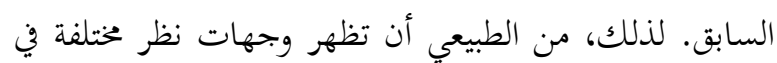
وضع الحدود العلمية لمصطلح الالتفات. اعتبارا على عدم وضوح حدود مفهوم وموضوع دراسة الالتفات، فهذه الظاهرة تؤثر في ظهور الاختلاف في وجهات النظر عن الالتفات في الدراسات البلاغية الحديثة. فعلماء

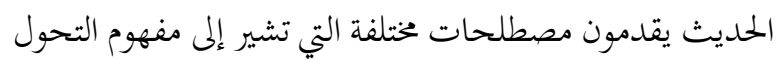

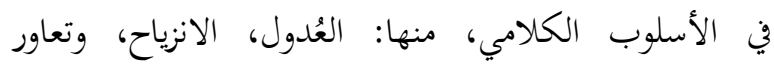

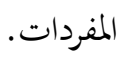

حسن طبل، عالم من علماء البلاغة الحديثة، يحاول أن

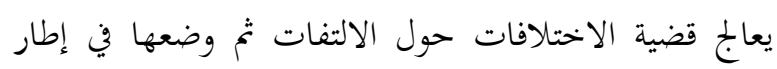
واضح. يؤكد حسن طبل أن الدراسات عن الالتفات في القرآن

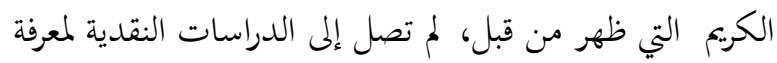

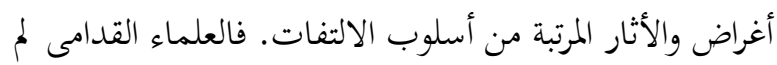
يقوموا عند دراستهم للإلتفات بالدراسات المتكاملة. وإنما 
والأثر الدلالي الذي يرمي إليه هذا الالتفات، هو أنّ المتكلم

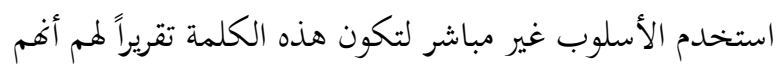

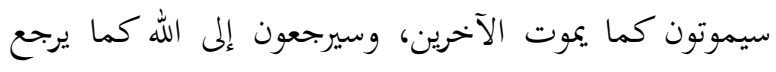

$$
\text { الآخرين، وسيحاسبون كما يحاسب الآخرين. }
$$

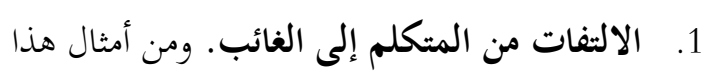

النوع من الالتفات، قوله تعالى في سورة البكوثر /108:

$$
: 2-1
$$

\section{إنَّاَ أَعْطَيْنَاكَ الْكَوْثَرَ}

ابتدأت الآية السابقة باستخدام ضمير المتكلمين "إنَّا

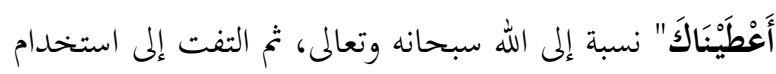

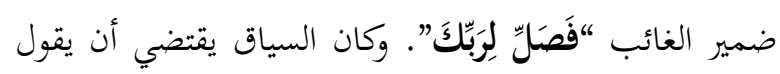

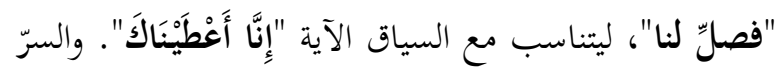

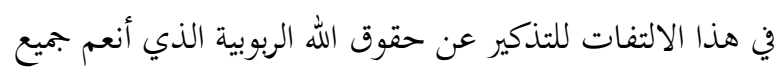

$$
\text { العباد، وهي العبادة له. }
$$

2. الالثفات من المخاطب إلى المتكلم. ومن أمثال هذا

$$
\text { النوع من الالتفات، قوله تعالى في سورة هود/11: 90: }
$$

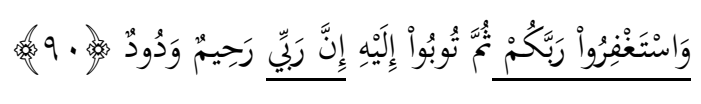

ففي المقطع الأول من الآية، كان سياق الكلام

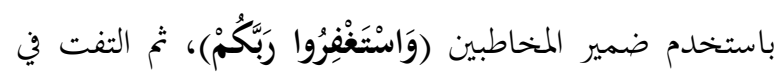

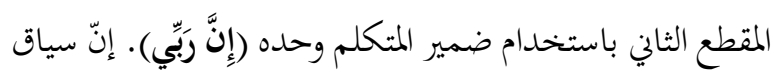
الكلام في هذه الآية يدور حول قصة قوم شيعب عليه السلام

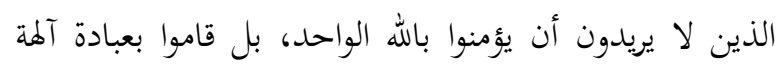
أجدادهم من قبل. ولذلك، بعد أن دعاهم شعيب ليستغفروا

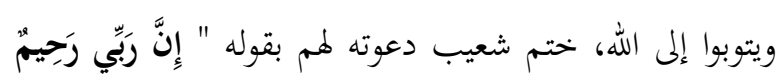

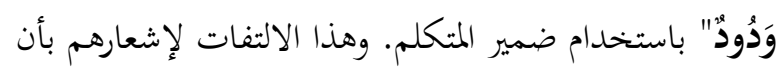

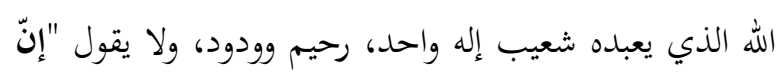
ربكم"، لأنّ أمة شعيب يعبدون ألهة كثيرة.

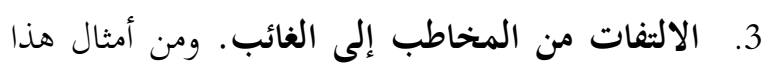

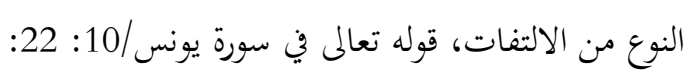

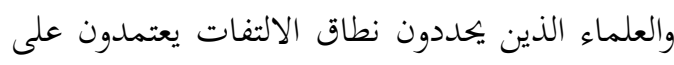

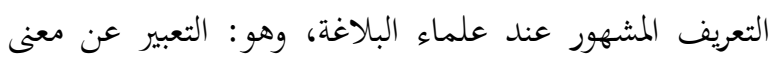
باستخدام طريق من الطرق الثلاثة. والطرق المقصودة هي:

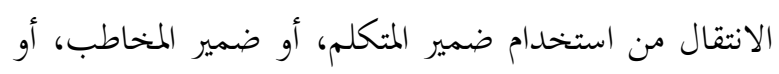

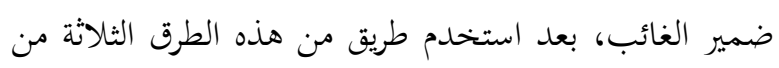

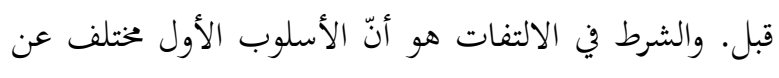

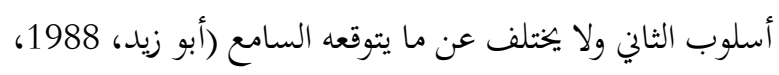
ص. 101). انطلاقا عن التعريفات السابقة ذكرها، فإنّ الالتفات عند

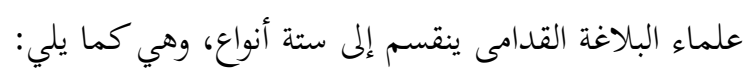
1. الالثفات في الكلام من المتكلم إلى المخاطبين.

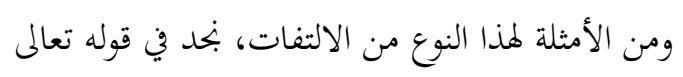

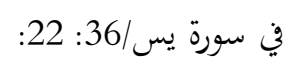

$$
\text { وَمَا لِي لَا أَعْبْدُ النَِّي فَطَرَيْ وَإِلَيْهِ تُرْبَعُونَ }
$$

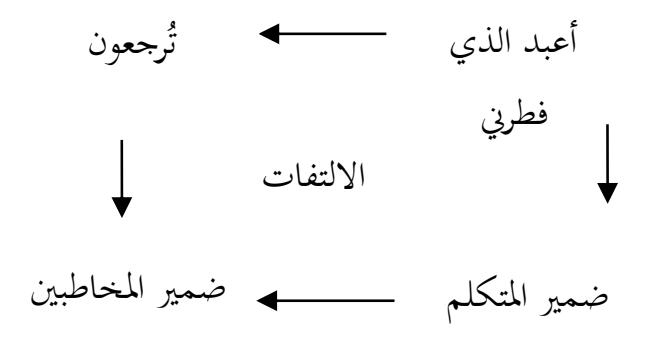

ففي بداية الآية، قال الرجل "وَمَا لِي لا أَعْبُدُ الَّندي

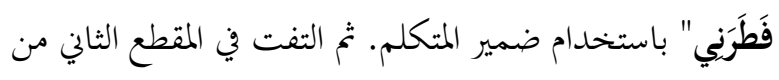
الآية بقوله "وإليه ترجعون" باستخدام ضمير المخاطب. فني بداية الآية، كان السياق يقتضي أن يقول "وإليه أرجع" ليتكافؤ سياق مطلع الآية مع آخرها.

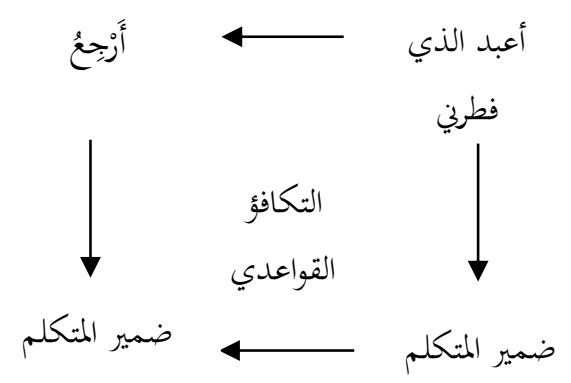


في قوله تعالى: "إِيَّكَكَ نَعْبُدُ وَإِيَّكَكَ نَسْتَعِينُ"، لأنّ التعبير عن

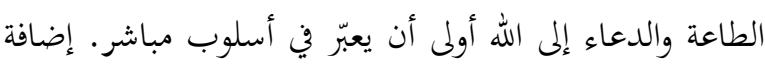

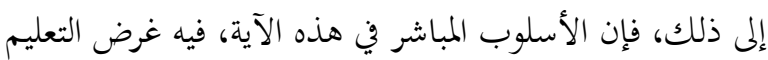
للعباد في الثناء إلى الله سبحانه. إذا لاحظنا أنواع الالتفات التي قدمناها سابقا، فإننا نلاحظ أنّ الأنواع المذكورة لا تستوعب جميع أنواع الالتفات التي

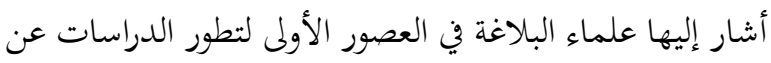

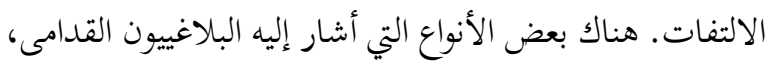
مثل: الانتقال من استخدام صيغة فعل الماضى إلى المضارع أو إو لئه عكسه، والالتفات من معنى إلى معنى آخر، وما أشبه ذلك، لم الم المعال يدخل ضمن التقسيم الشائع عند علماء البلاغة المتقدمين. تطور تصنيف الالتفات في الدراسات البلاغية عند علماء المتأخرين

انطلاقا من التعريف العام، ذهب علماء البلاغة

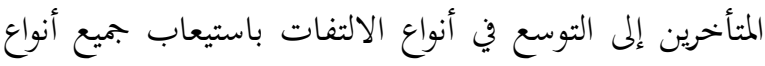

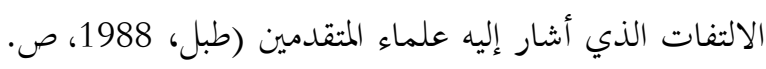

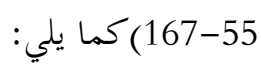

\section{1. الالتفات في استخدام صيغة صرفية معيّنة إلى صيغة

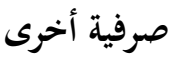

يتحقق الالتفات في هذا المجال كلما تخالفت في استخدام صيغة صرفية من مادة معجمية واحدة. وتتمثل هذه

$$
\text { الصورة أنواعا عديدة، وهي: }
$$

أ. استخدام متبادل بين صيغتي الصرف، حيث أنّ وهدئ

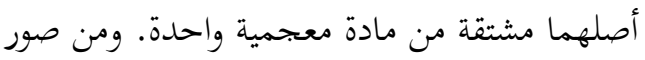
هذا النوع هو الانتقال في استخدام صيغة الفعل على سلى

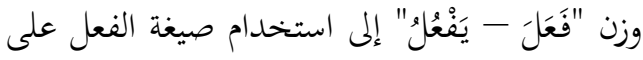

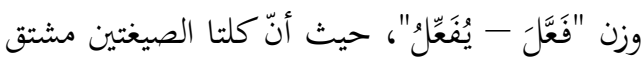

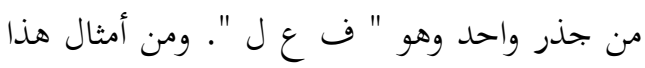

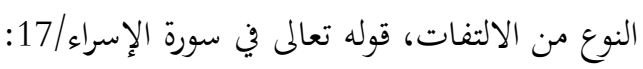

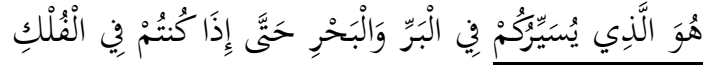

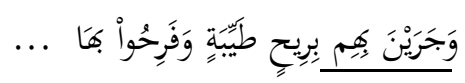
يسير سياق الكلام في مطلع الآية السابقة باستخدام

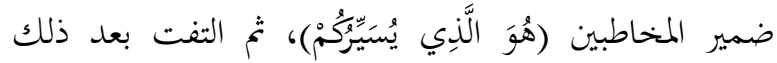

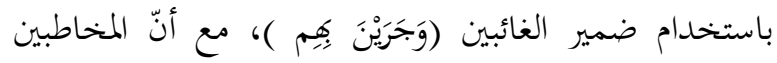

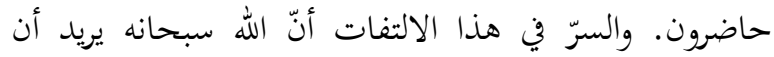
يشعرهم بأنّ مثل هذه الحالة ليست مقصورة على هلى المخاطبين فحسب، بل تنطبق مع كل من ينكرون ألوهية الله وينسون نعمه.

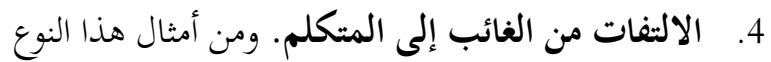
من الالتفات، قوله تعالى في سورة فاطر /35: 9:

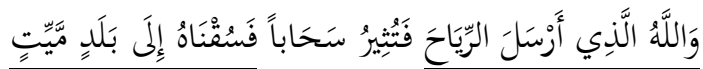

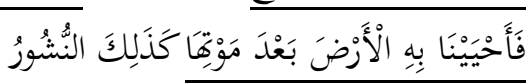

ففي مطلع الآية، استخدم القرآن ضمير الغائب في

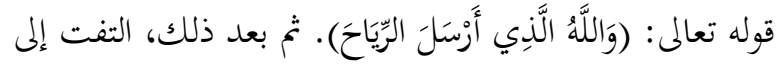

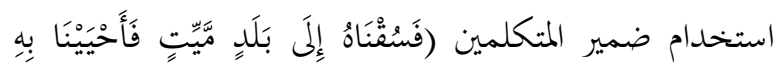

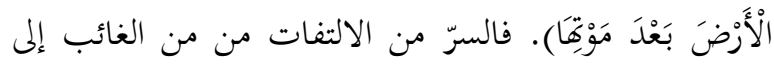

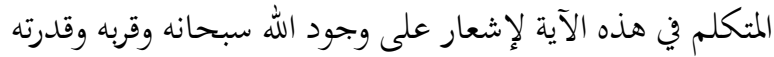

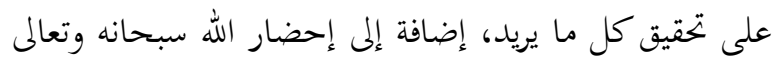

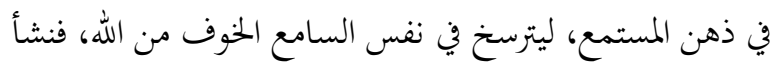
مع ذلك موقف الطاعة والخضوع. 5. الالتفات من الغائب إلى المخاطب. ومن أمثال هذا النوع من الالتفات، قوله تعالى في سورة الفاتحة/1: 2-5:

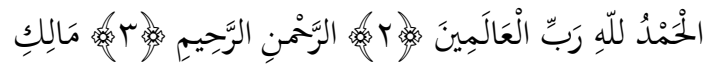
يَوْمُ الدّيّنِ وصف الله سبحانه وتعالى نفسه باستخدام صيغة

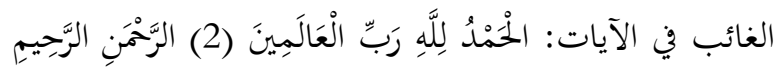

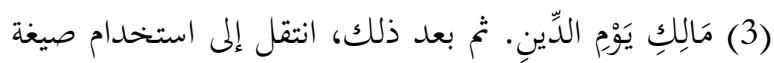

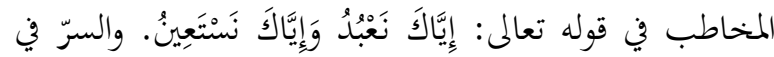

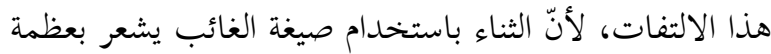

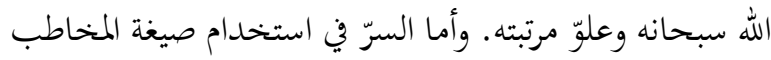


اسم المرة "ضلالة" لغرض المبلاغة في نفي تلك التهمة. وذلك

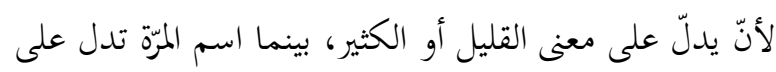

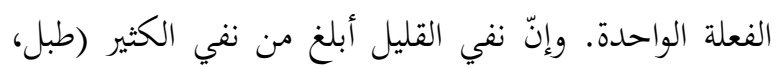

$$
\text { 1998، ص. (71) }
$$

\section{ج. الالتفات بين صيغ الأفعال}

إذا قرأنا الآيات القرآنية قراءة متأنية، وجدنا أن النيع هناك آيات

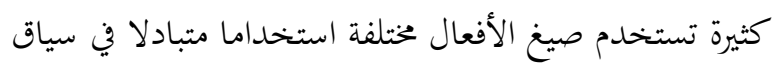

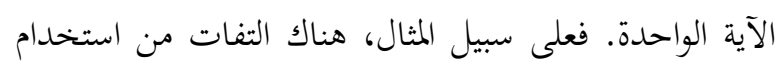

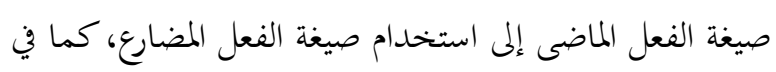
قوله تعالى في سورة الحج/22: 65:

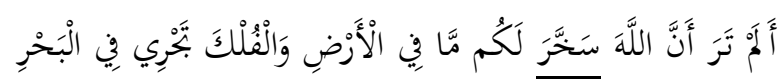

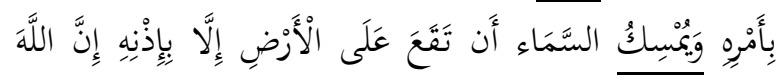

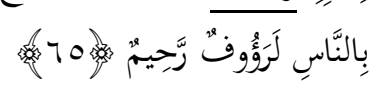

في الآية السابقة التفات من استخدام الفعل الماضى

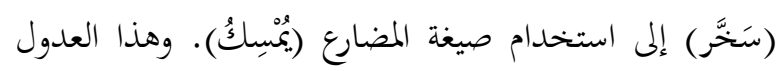
لبيان الفرق بين صور حدوث الأفعال. فإنّ تسخير الله سبحانه

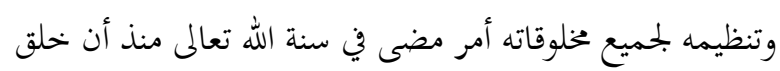

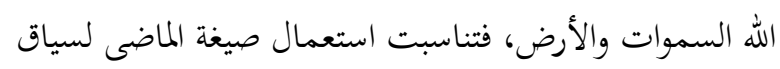

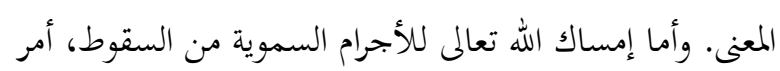

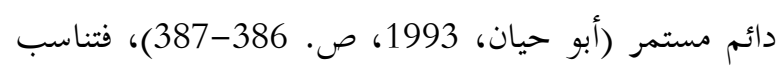
مع ذلك صيغة المضارع مع سياق الآية.

\section{د. الالثفات من صيغة الاسم إلى صيغة الفعل}

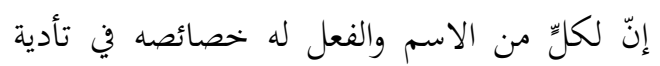

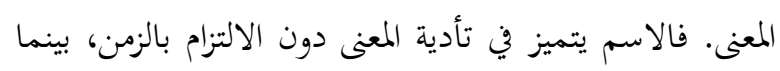

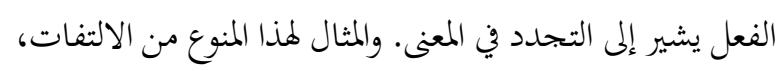

$$
\text { في قوله تعالى في سورة آل عمران/3: } 134
$$

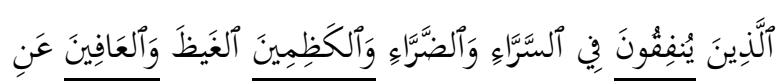

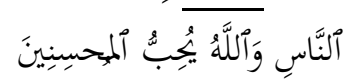

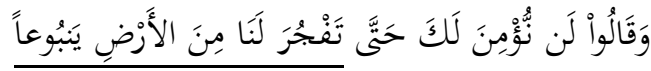

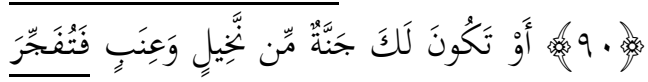

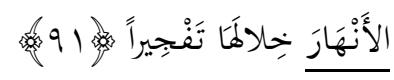

فلقد جرى الآية الكريمة السابقة على استخدام صيغة

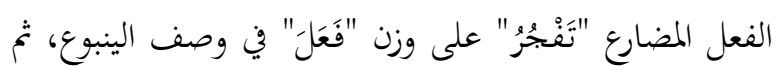

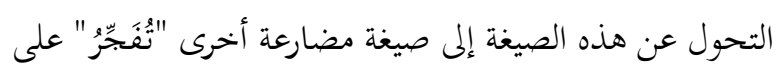

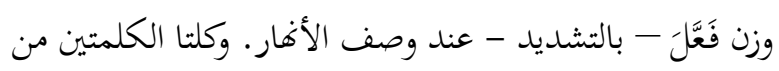

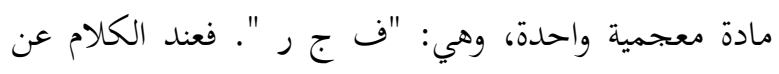

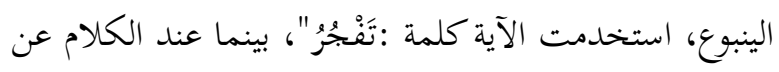

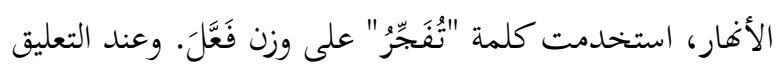
على هذه الآية، قال السّمرّائي، أنّ استخدام صيغتي صرفيتين متبادلتين في الآية ليتناسب سياق الآية مع المعنى الذي يراد

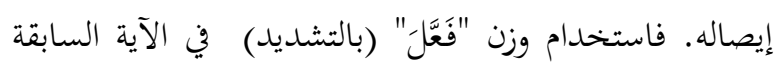

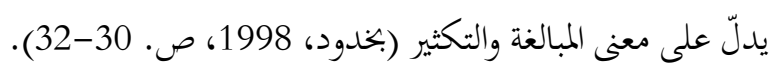
ولذلك، استخدم كلمة تَفْجُرُ عند الكلام عن الينبوع، لأنّ الماء

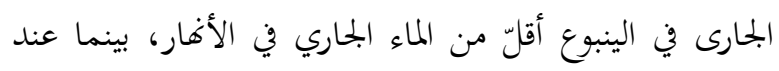

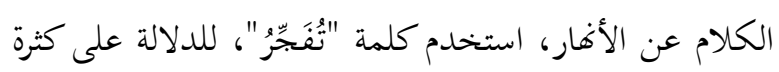
الماء الجاري في الأهار بالنسبة إلى ماء الينبوع.

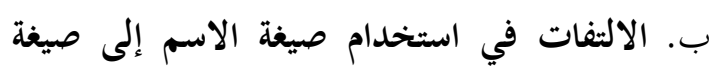

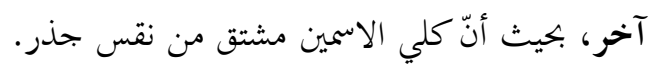

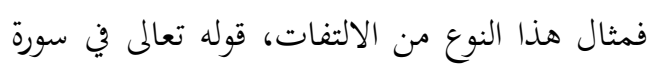

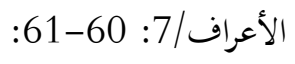

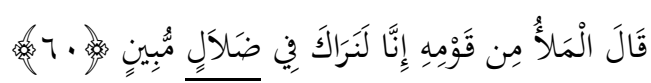

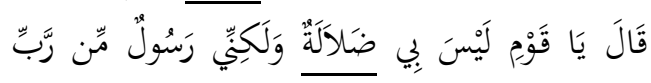

$$
\text { الْعَالَمِينَ }
$$

في الآية السابقة، فيها التفات من كلمة "ضلال" إلى كلمة

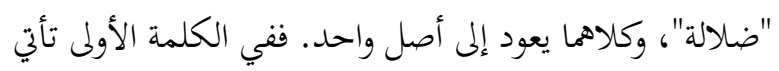

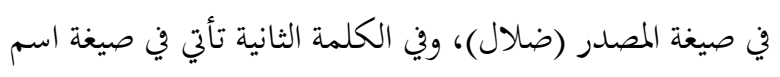
المرّة (ضلالة). فلقد كان مقتضى السياق أن ينفي نوح قممة

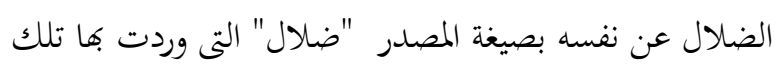

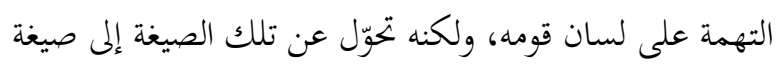


عظمته سبحانه وقوته في تحقيق ما يريد، فإنه يحترم نوح عليه

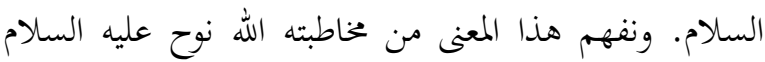

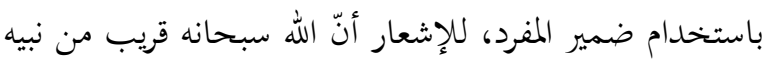

$$
\text { نوح عليه السلام. }
$$

\section{3. - 3. - الالتفات في الضمائر}

الالتفات في الضمائر هنا هو العدول في استخدام

الضمائر من ضمير الغائب إلى المخاطب، ومن الغائب إلى هن

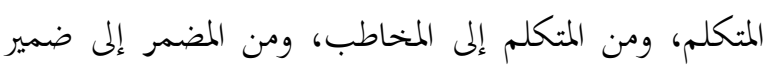

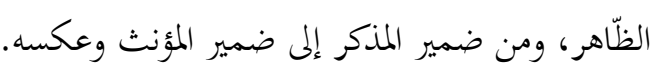

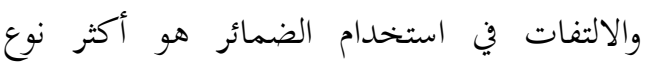
الالتفات اهتماما عند جمهور علماء البلاغة. فمثال الالتفات

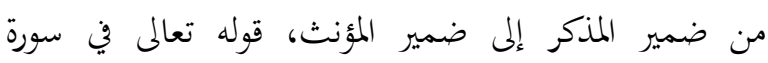

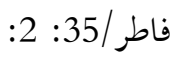

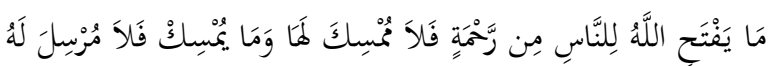

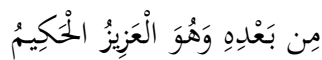

ففي الآية السابقة، التفات من استخدام ضمير العائد

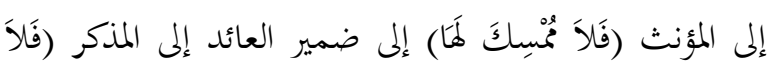

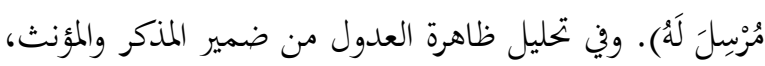
علّل الزخشري (1998، ص. 139) بأنّ استخدام ضمير المؤنث

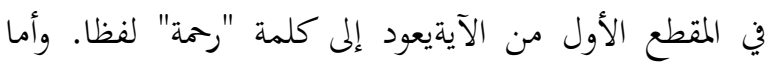
استخدام ضمير المذكر في المقطع الثاني من الآية، أنه مطلق

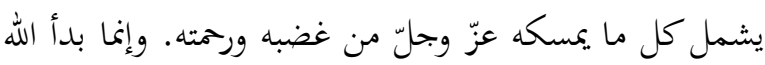

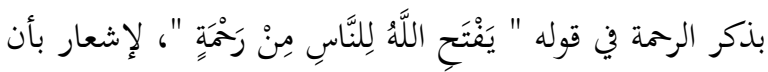

$$
\text { رحمته سبقت غضبه سبحانه وتعالى. }
$$

\section{4. الالتفات في استخدام الأدوات النحوية}

إذا قرأنا الآيات القرآنية قراءة متأنية، وجدانا أمثلة كثيرة

للالتفات في استعمال الأدوات النحوية. فعلى هذا، فإن العلماء

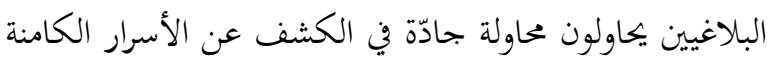
وراء هذه الظاهرة اللغوية. ومن أمثلة الالتفات في الأدوات

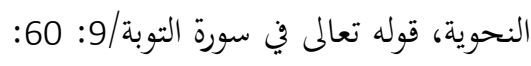

بيّن الله سبحانه وتعالى في الآية السابقة عن صفات

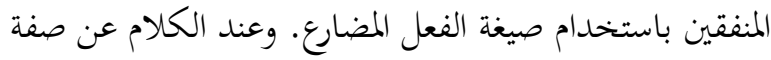
"كظم الغيظ" (والكاظمين الغيظ) وصفة "العفو" (والعافين عن

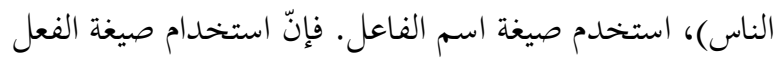
المضارع (يُنْفُقُونْ) يشير إلى معنى التجدد أو الاستمرارية.

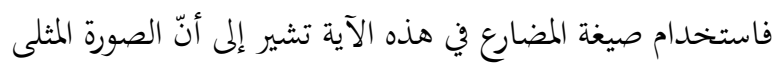
لصفة الإنفاق لا تتحقق إلا بتجددها على اختلاف الظروف

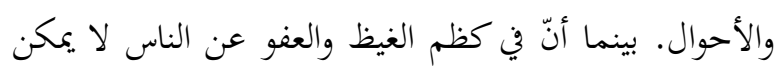

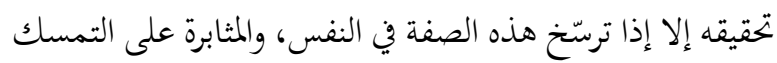

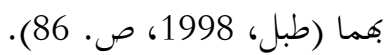
2. 2. الالثفات في العدد الالتفات العددي عند ابن الأثير كما نقل عنه كفايت الله هماني (2016، ص. 152)، هو الرجوع من خطاب التثنية

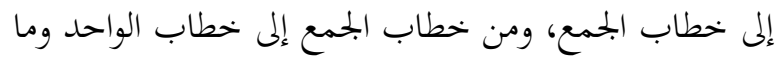

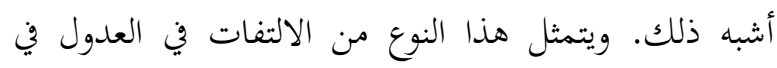

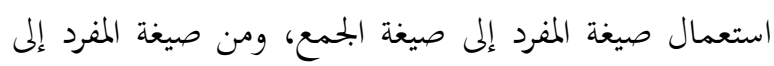

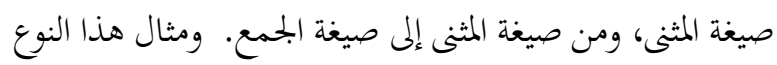
من الالتفات، قوله تعالى في سورة المؤمنون/23: 27:

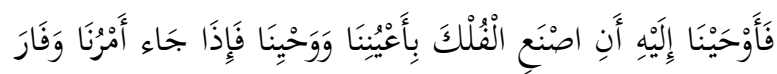

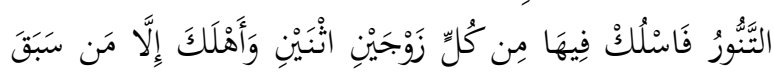

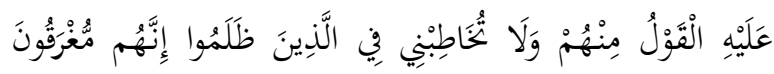

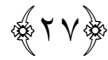

ففي الآية السابقة التفات من ضمير الجمع إلى ضمير

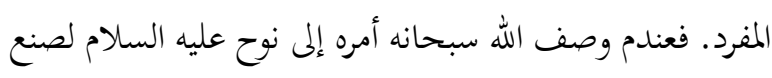

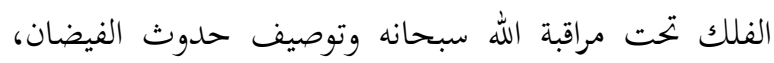

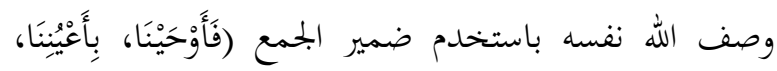

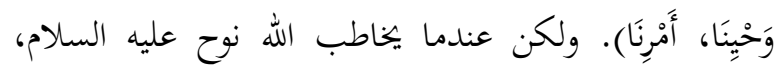

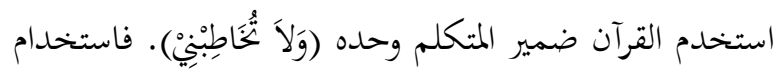

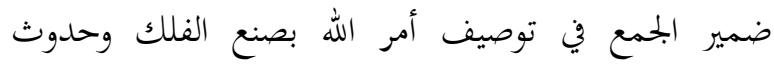
الفيضان، للتوكيد والإشارة إلى عظمة الله وقدرته في تدمير قوم نوح عليه السلام. وحينما خاطب الله سبحانه وتعالى نوح عليه

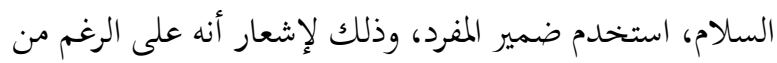




\section{5. - 5. الالتفات في البناء النحوي}

المقصود من الالتفات في البناء النحوي، هو إعادة عنصر

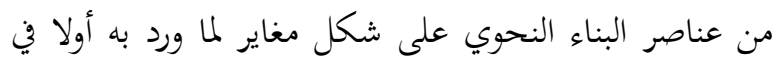
نفس التعبير أو السياق، بحيث يكون المعنى الذي يؤديه التعبير

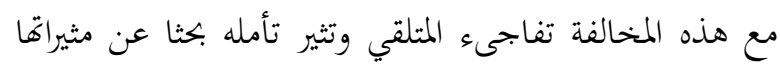

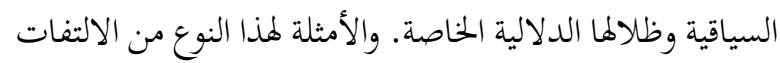

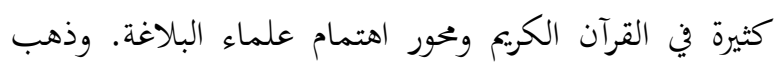

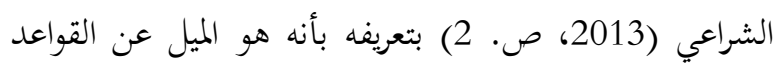

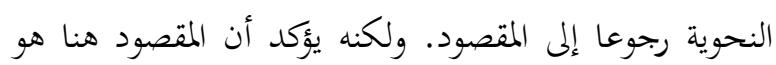

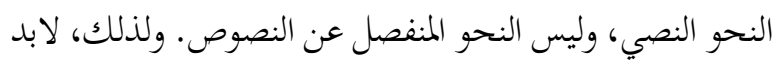

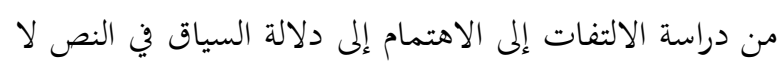

في القاعدة النحوية المعيارية نفسها.

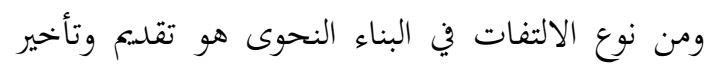

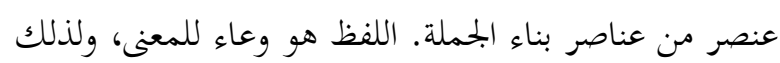

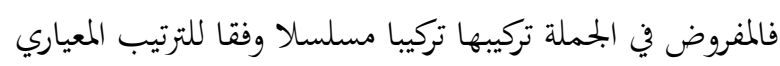

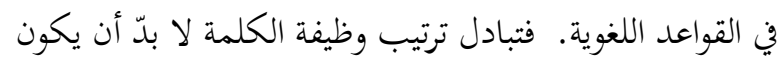
هناك أغراض معنوية يرمي إليه هذا التبادل أو التقديم والتأخير.

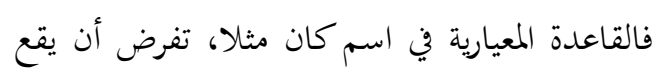

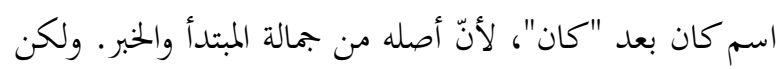
مع ذلك، بند في التراث العربي وفي التعبيرات القرآنية ظاهرة العدول عن هذه القاعدة، في صور تبادل موقع الكلمة بعضها عن بعض في الجملة. فمثال ذلك، قوله تعالى في سورة الروم/30:

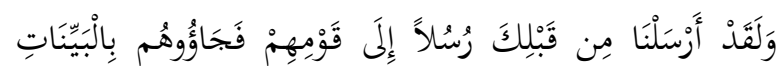

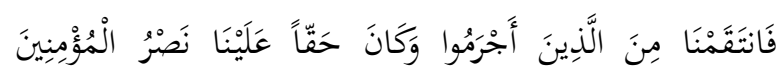

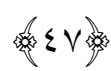

وموضع الاهتمام في الآية السابقة هو قوله تعالى:

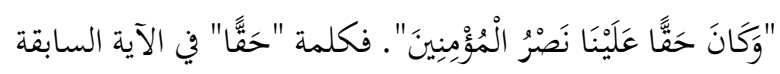
هي خبر المقدم لـ "كان"، وكلمة "نَصر" هي مبتدأ مأخّر. المفروض وفقا للقاعد المعيارية المفروض أن يكون ترتيب الكلمة

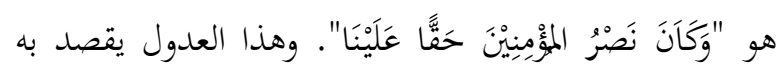
التسارع إلى تأكيد حق المساعدة للمؤمنين، فحدث لمعند في الكلمة

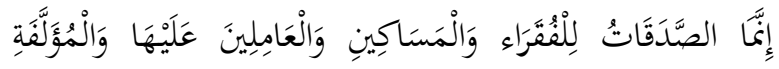

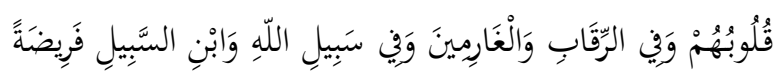

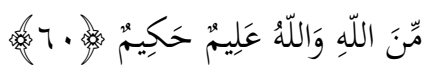

إذا نظرنا إلى الآية السابقة نظرة سريعة، فإننا نلمح إلى

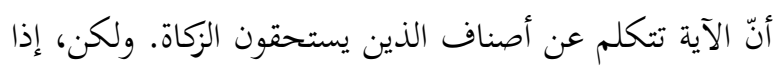

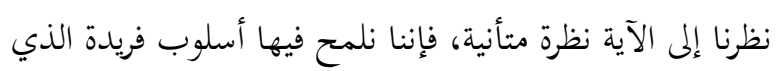

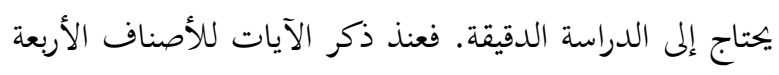
الأولى الذين يستحقون الزكاة (للفقراء، والمساكين، والعاملين عليها، والمؤلفة قلوبهم)، استخدم القرآن لام للملكية (إنَّمَا

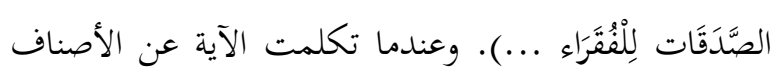

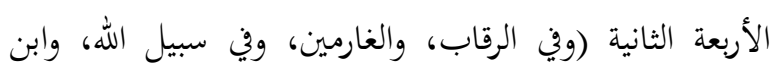

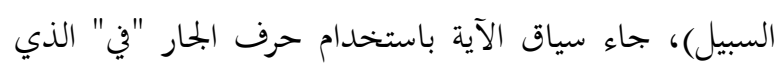
يتضمن معنى الظرفية.

إنّ استخدام حرف اللام الجحارة في الآية للدلالة على لفرقية. الملكية. فإنّ الفقراء والمساكين، يستحقون أخذ الزكاة ما داموا

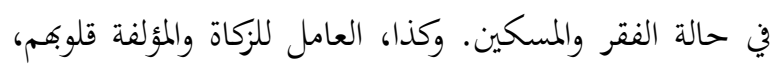

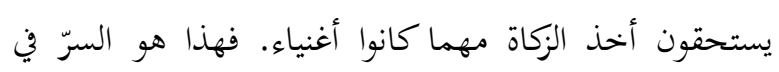
استخدام حرف اللام الجارة في هذه الآية حيث أن هؤلاء

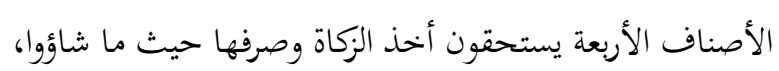

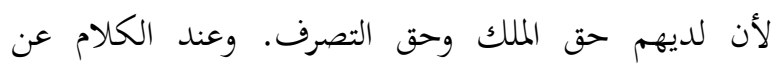

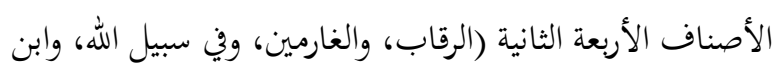

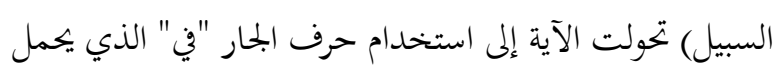

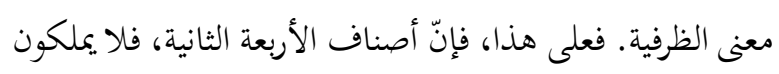
ما يصرف نحوهم من الزكاة، ولكن في المصالح التي تتعلق بهم. فالمال الذي يصرف في الرقاب إنما لأجل دفع التكلفة في فلكّ التصن

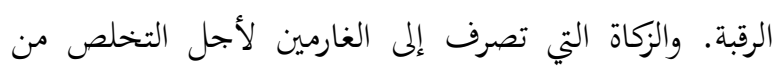

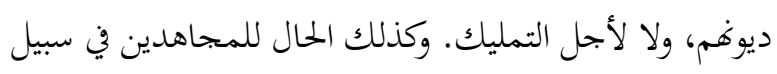

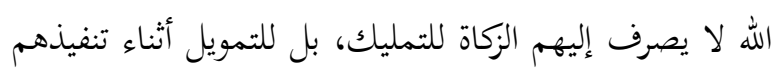

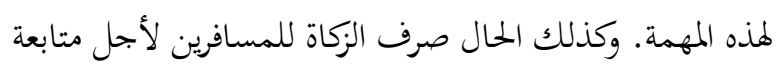

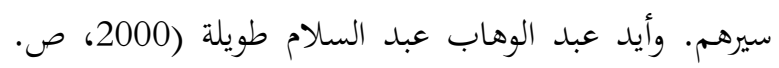

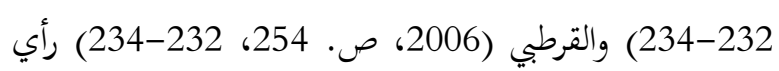
محمد عبده في هذا المفهوم للآية. 
التوسّع لا يعنى أن العلماء المتأخرين خرجوا من القواعد التي قد

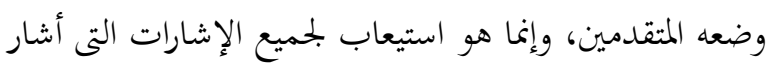

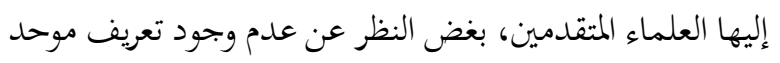

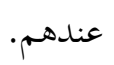

\section{الخلاصة}

الالتفات هي أسلوب من أساليب التعبير في علم

البلاغة. واختلف العلماء في تقديم التعريف للالتفات. وهذه الظاهرة تشير إلينا أنّ موضوع الالتفات في الدراسات البلاغية

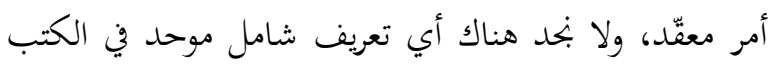

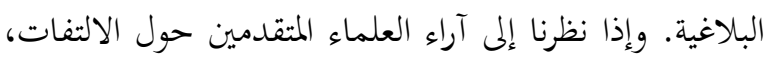
بند أن هناك مصطلحات مختلفة تعود إلى معنى الالنفات.وفي

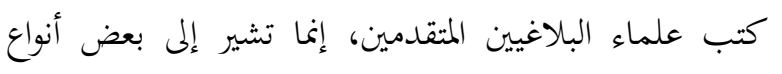

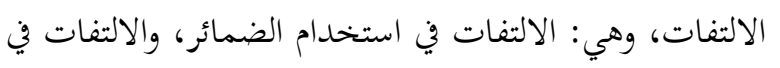
استخدام صيغة الأفعال، والالتفات من معنى إلى معنى آخر.

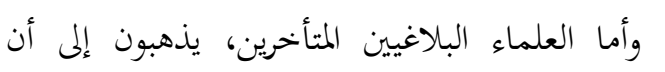
الالتفات هي العدول في أسلوب التعبير على الوجه العام. ولذلك، فالعلماء المتقدمون يرون جميع أنواع العدول في الكلام في ضمن أسلوب الالتفات. فعلى هذا التعريف العام، دراسوا

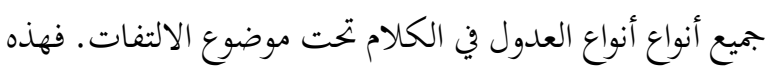
المحاولة في التوسيع، أبدعوا كثيرا من أنواع الالتفات، من أمثال:

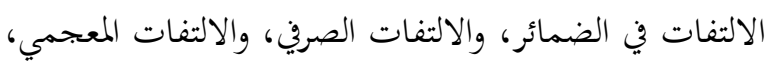
والالتفات في الصيغة (المذكر والمؤنث)، والالتفات في العدد (المفرد والمثنى والجمع)، وما أشبه ذلك. بغض النظر عن التحديد أو التوسّع في موضوعات

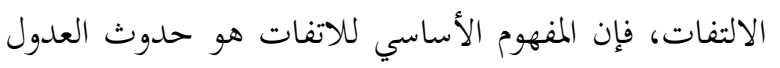

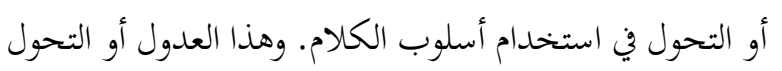
نوع من الابداعية اللغوية. والغرض من كل هذه الالتفاتات

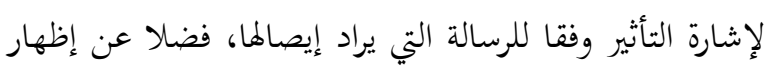
ثراء اللغة العربية، وخاصة في القرأن الكريم.
تقديم ليكون هذا المعنى أول ما سمعه المتلقي (الخالدي، 2000،

ص. 262)

6. الالتفات المعجمي الالتفات المعجمي هو العدول في الاستخدام بين

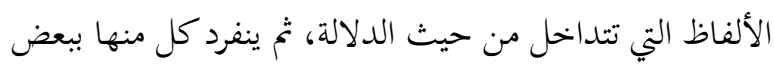

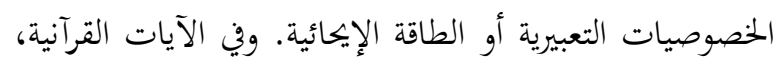
بنحد في كثير من الآيات التي استخدمت استخداما متبادلا بين

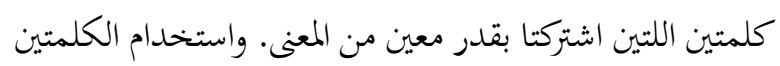
في شكل متبادل في سياق واحد، له أثر دلالييرمى إليه.

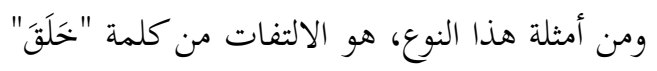

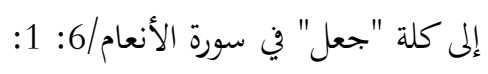

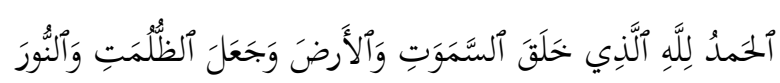

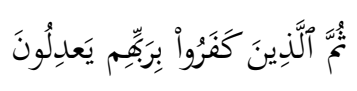

فكلمة "جَعَلَ" لغة بمعنى التهيئة أو تصيير الشيء أو

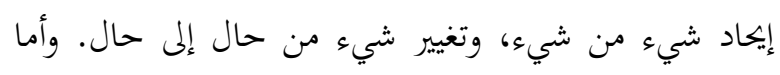

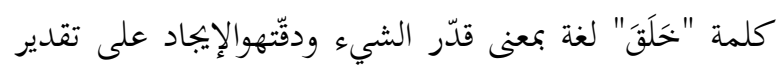

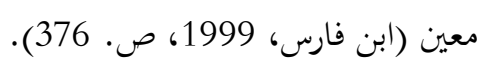
الالتفات من كلمة "جَعَلَ" إلى كلمة "خََلَقَ" في سورة الأنعام التي ذكرنا سابقا يؤكد على وجود الفروق المعنوية في

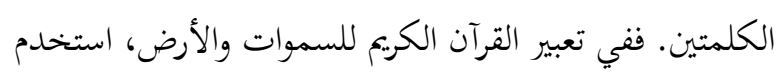
القرآن كلمة "خلق"، لأن خلق السموات والأرض هو الإيجاد على تقدير من غير مثال سابق. بينما عبرّ القرآن كلمة

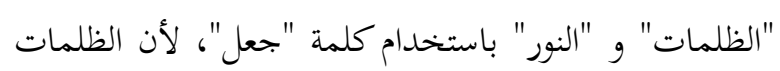
والنور إنما هي تصيير من شيء. فالظلمات والنور جزء لا يتجزء

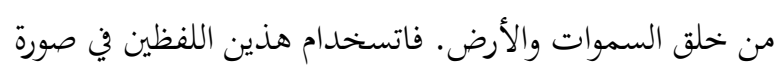

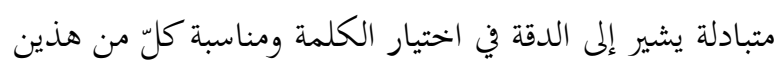
الكلمتين مع سياق الكلام والمعنى الذي يراد إيصاله. إنّ التوّسع في موضوعات الالتفات الذي ذهب إليه

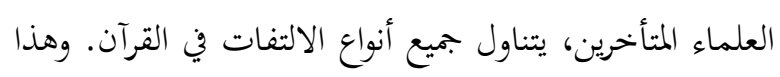




\section{المراجع}

ابن قطيبة الدنواري، أبو محمد عبد الله بن مسلم. (2007). تأويل مشكل القرآن، تحقيق إبراهيم شام الدين. بيروت: دار الكتب العلمية. ابن منظور. (2013) ( لسان العرب، الجزء الثامن. القاهرة: دار الحديث.

أبو زيد، زريمة محمود. (1998). علم المعاني: دراسة وتحليل. الطبعة الأولى؛ القاهرة: مكتبة وهبة. الأندلوسي، محمد بن يوسف أبو حيان. (1993). تنسير بحر المحيط. الجزء الرابع. الطبعة الأولى؛ بيروت: دار الكتب العلمية. بخدود، علي بهاء الدين. المدخل الصرفي (1998). الطبعة الأولى؛ بيروت: المؤسسات الجامعية للدراسات والنشر والتوزيع. الداية، فايز . (1996). علم الدلالة العربي: النظرية والتطبيق. الطبعة الثانية؛ دمشق: دار الفكر. طبل، حسن. (1998). أسلوب الالثنات في البلاغة القرآنية. الطبعة الأولى؛ القاهرة: دار الفكر العربي. طويلة، عبد الوهاب عبد السلام. (2000). أثر اللغة في اختلاف المجتهدين. الطبعة الثانية؛ القاهرة: دار السلام. المبرّد، أبو العباس محمد بن يزيد. (1998). الكامل في اللغة والأدب، الجزء الثالث، تحقيق عبد الحميد هندوي. المملكة العربية السعودية: وزارة الشؤون الإسلامية والأوقاف والدعوة والإرشاد.

الميداني، عبد الرمن حسن هبنكة. (1996). البلاغة العربية أسسها وعلومها وفنوغا. الجزء الأول. الطبعة الأولى؛ دمشق: دار القلم. ناصف، حفني وأصحابه. (2007). دروس البلاغة. الطبعة الأولى: باكستان: مكتبة المدينة. العسكري، أبو هلال. (1952). كتاب الصناعتين، تحقيق علي محمد البجاوي ومحمد أبو الفضل إبراهيم. القاهرة: عيسى الباب الحلبي. فالح، جليل رشيد. (1984). فنّ الالتفات في مباحث البلاغيين. بحلة الأدب المستنصرية. العدد التاسع، الرقم العاشر، 63-98. الفيل، توفيق. (دون سنة). بلاغة التراكيب. القاهرة: مكتبة الأدب.

القرطبي، أبو عبد الله حمد بن أبي بكر. (2006). الجامع لأحكام القرآن، الجزء العاشر. الطبعة الأولى؛ بيروت: مؤسسة الرسالة. القزويني، الخطيب. (2003). الإضاح في علوم البلاغة: المعاني والبيان البديع. الطبعة الأولى؛ بيروت: دار الكتب العلمية. الرازي، أبو الحسين أحمد بن فارس بن وكريا. (1999). معتمم مقاييس اللغة. الجزء الأول. تحقيق إبراهيم شمس الدين. الطبعة الأولى؛ بيروت: دار الكتب العلمية.

الشراعي، عبد الله أحمد بن أحمد. (2013). العدول النحوي في القرآن الكريم: إعجاز لغوي آخر. بحلة الباحث الجامعي للعلوم الإنسانية، 31، 1-15. الخالدي، صلاح عبد الفتاح. (2000). إعجاز القرآن البياني ودلائل مصدره الرباني. الطبعة الأولى؛ عمان: دار عمّار. الخرشة، أحمد غالب النوري. (2008). أسلوبيات الإنزياح في النص القرآني، أطروحة. يوردانية: قسم اللغة العربية جامعة معتة. 


$$
\begin{aligned}
& \text { الزخشري، أبو القاسم محمود بن عمر . (1998). الكشاف عن حقائق غوامض التنزيل وعيون الأقاويل في وجوه التنزيل، تحقيق عادل أحمد عبد الموجود و } \\
& \text { علي محمد معوض، الجزء الخامس. الطبعة الأولى؛ الرياض: مكتبة العابكان. } \\
& \text { الزركشي، بدر الدين محمد بن عبد الله. (1984). البرهان في علوم القرآن، الجزء الثاني، تحقيق محمد أبو الفضل إبراهيم. الطبعة الثالثة؛ القاهرة: دار التراث. }
\end{aligned}
$$

Idris, Mardjoko, (2019). Gaya Bahasa Iltifat dalam Alquran. Jurnal al-Lubab. Vol. 5 No. 1, 23-86.

Makinuddin, Moh, (2018). Mengenal Uslub dalam Struktur Kalimat dan Makna, Jurnal Miyah, Vol. 14, No. 2.

Susiawati, Wati. (2015). Lafadz dan Makna dalam Perspektif Pemikiran Ibn Jinni. Jurnal Arabiyat, 2, 167-177.

Wehr, Hans. (1976). A Dictionary of Modern Written Arabic (3rd edition). New York: Spoken Language Service. 
LiNGUA Vol. 14, No. 2, December 2019 • ISSN 1693-4725 • e-ISSN 2442-3823 